\title{
Fatigue Behavior of 2198-T8 Aluminum-lithium Alloy with Riveted Lap Joints
}

\author{
An CHEN ${ }^{*}$, Shan-Shan LI, Fei XU and Deng-Ke DONG \\ Aircraft Strength Research Institute of China, Xi'an 710065, China \\ Email: andychen1986@163.com \\ ${ }^{*}$ Corresponding author
}

\begin{abstract}
Keywords: 2198-T8 aluminum-lithium alloy, Riveted lap joints, Detail fatigue rating (DFR), Fatigue
\end{abstract} fractography.

\begin{abstract}
The detail fatigue rating (DFR) value of riveted lap joints made of 2198-T8 aluminum-lithium alloy was measured and calculated based on the fatigue test results. Fatigue fracture surface morphology was examined by scanning electron microscopy (SEM). The results indicate that DFR value of 2198-T8 alloy is 83.09MPa. Fatigue fractography shows that the fatigue striations of 2198-T8 are smooth and neat, so 2198-T8 alloy have superior fatigue properties. The study can be used to select suitable materials from the fatigue strength design and fatigue life evaluation of the civil aircraft.
\end{abstract}

\section{Introduction}

Aluminum-lithium alloys have been widely used in various structural components of aircraft because of their low density, high elasticity modulus and excellent fatigue property[1]. The addition of lithium ( $\mathrm{Li}$ ) in aluminum $(\mathrm{Al})$ alloy is beneficial to weight reduction of $\mathrm{Al}$ alloys. The density of $\mathrm{Al}$ alloys can be lowered by 3\% as per $1 \mathrm{wt} \% .2198$ alloy is the third generation of Al-Li-Cu alloy which has excellent corrosion resistance, superior damage tolerance and good weldability. Some investigators had studied the static and fatigue performance of the $2198 \mathrm{Al}-\mathrm{Li}$ alloy [2,3].

Riveted lap joints are being utilized extensively in civil aircraft structures use to their cost effective, flexible and high resilience. Fatigue properties of riveted lap joints determine the safety and reliability of aircraft in service life. Lots of research has been carried out on the mechanical and fatigue behavior of traditional alloys (e.g.2024, 2524 and 7050) [4,5]. However, fatigue behavior of riveted joints in aluminum-lithium alloys has not been investigated extensively.

The objective of this study therefore was to obtain the DFR value of riveted lap joints made of 2198-T8 Al-Li alloy by statistical analysis of experimental data. The fractography of the fatigue crack initiation and propagation was observed by scanning electron microscopy.

\section{Experimental Procedure}

The material used for the present investigation was 2198-T8 Al-Li alloy that was received in sheet form with nominal thicknesses of $1.8 \mathrm{~mm}$. The chemical compositions of 2198-T8 Al-Li alloys were listed in Table 1.

Table 1. Chemical composition of 2198-T8 (mass fraction, \%).

\begin{tabular}{ccccccccccc}
\hline $\mathrm{Si}$ & $\mathrm{Fe}$ & $\mathrm{Cu}$ & $\mathrm{Mn}$ & $\mathrm{Mg}$ & $\mathrm{Zn}$ & $\mathrm{Ag}$ & $\mathrm{Li}$ & $\mathrm{Zr}$ & $\mathrm{Ti}$ & $\mathrm{Al}$ \\
\hline 0.08 & 0.1 & 3.2 & 0.5 & 0.52 & 0.35 & 0.3 & 0.8 & 0.12 & 0.1 & other \\
\hline
\end{tabular}

The geometrical dimensions of the riveted lap joints specimens were shown in Fig. 1. All specimens were $300 \mathrm{~mm}$-long, $40 \mathrm{~mm}$-wide sheets, with $60 \mathrm{~mm}$-long lap joints made of three two-rivet rows. All rivets were NAS1097AD6, spaced $20 \mathrm{~mm}$ along the width of the specimen. 


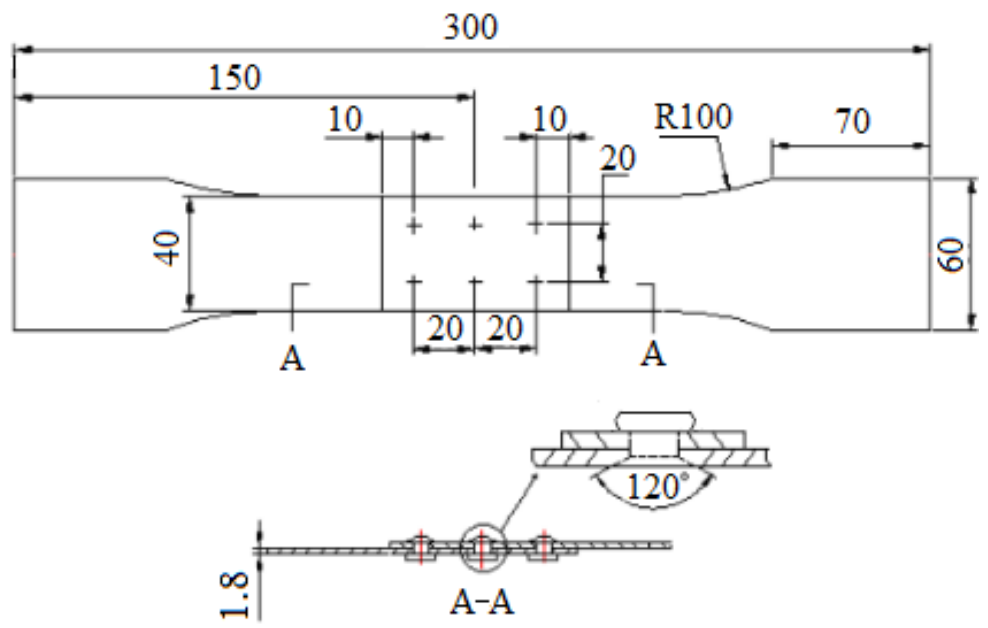

Fig. 1. Geometry dimension of riveted lap joins specimen.

Fatigue tests were carried out on INSTRON-8801 material testing machine (Fig. 2) with a load cell of $100 \mathrm{kN}$. All tests were performed in load control mode at a frequency of $15 \mathrm{~Hz}$. Load ratio was kept constant for fatigue tests and equal to $\mathrm{R}=0.06$, which is the typical wave form for testing aeronautical materials. Fatigue tests were conducted according to HB5287-96 specification. In all performed tests, only the number of cycles until failure is recorded.

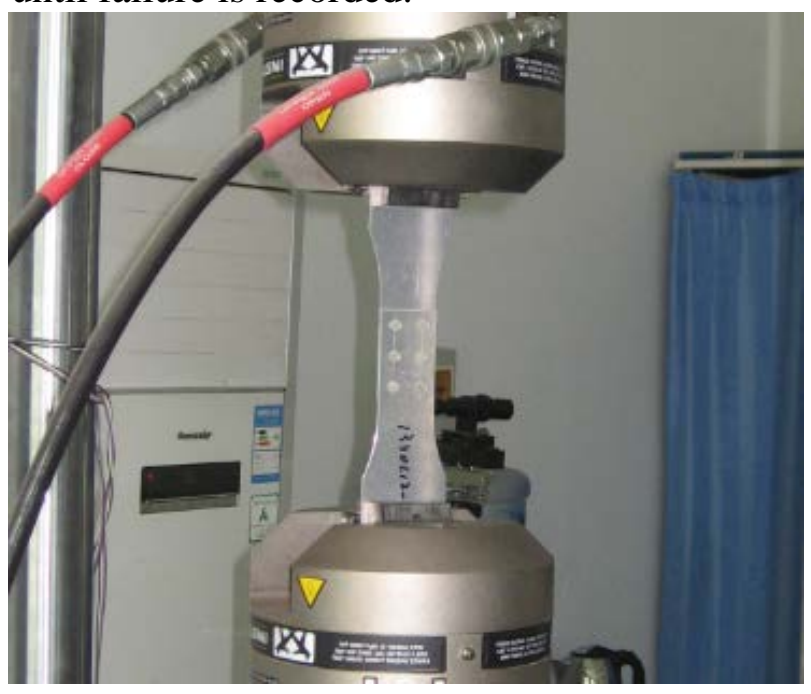

Fig. 2. Riveted lap joints test.

\section{Test Results and Analysis}

Effective number of fatigue life is less than five to ensure the reliability of the experiment, and suitable stress level chosen is important. Experimental fatigue results of 2198-T8 Al-Li alloy with riveted lap joints can be seen in Table 2 under stress of $90 \mathrm{MPa}$.

Table 2. Test results of fatigue life

\begin{tabular}{cllllll}
\hline$\sigma_{\max }(\mathrm{MPa})$ & \multicolumn{7}{c}{ fatigue life (cycle) } \\
\hline 90 & 193825 & 234534 & 250459 & 216488 & 182832 & 254520 \\
\hline
\end{tabular}

The detail fatigue rating method has been introduced for a fatigue analysis of commercial aircraft structures by Boeing since 1980s. The DFR represents the maximum nominal stress, which the structure can withstand, when it is subjected to a constant amplitude fatigue loading with an asymmetry of $\mathrm{R}=0.06$, resulting in a fatigue life of 100,000 cycles with a level of reliability of $95 \%$ and a 95\% confidence level for a particular structural fatigue detail. Nowadays, this method is widely 
used for fatigue life analyses of aircraft structures because of its advantages of simplicity and convenience [6,7].

Weibull distribution is one of the most widely used lifetime distributions in reliability engineering, which is versatile to take on the characteristics of other types of distributions. It is generally assumed that fatigue life of material follows two-parameter Weibull distribution because of processing precision, genetic defects and environmental factors. Its probability density function (PDF) can be written as[8,9]:

$$
F(N)=1-\exp \left[-\left(\frac{N}{\beta}\right)^{\alpha}\right]
$$

where $\beta$ is characteristic fatigue life, $\alpha$ is the scale parameter, which determines the shape of the distribution density curve of Weibull distribution.

According to maximum likelihood method, the point estimation of characteristic life can be expressed as:

$$
\hat{\beta}=\left(\frac{1}{n} \sum_{i=1}^{n} N_{i}^{\alpha}\right)^{\frac{1}{\alpha}}
$$

Probability distribution function of Weibull distribution can be changed to the standard linear equations by mathematical transformation. The slope of standard linear equations is $\alpha$. The value can be obtained, $\alpha=4$, according to number of experimental statistical data by Boeing for aluminum alloy.

The reliable fatigue life $\mathrm{N}_{95 / 95}$ can be determined by:

$$
N_{95 / 95}=\frac{\hat{\beta}}{S_{C} \cdot S_{R} \cdot S_{T}}
$$

where $\widehat{\beta}$ is the point estimation of characteristic fatigue life, $\mathrm{S}_{\mathrm{C}}$ is the confidence level factor, $\mathrm{S}_{\mathrm{R}}$ is the reliability level factor and $\mathrm{S}_{\mathrm{T}}$ is the specimen factor.

$\mathrm{S}_{\mathrm{C}}$ with a $95 \%$ confidence level can be seen in the Table 3.

Table 3. Confidence coefficient

\begin{tabular}{cccccccc}
\hline $\mathrm{n}$ & 2 & 3 & 4 & 5 & 6 & 7 & 8 \\
\hline $\mathrm{S}_{\mathrm{C}}$ & 1.24 & 1.195 & 1.175 & 1.16 & 1.15 & 1.13 & 1.125 \\
\hline
\end{tabular}

The reliability level factor $S_{R}$ is calculated as:

$$
S_{R}=\left(\ln \frac{1}{R_{S}}\right)^{-1 / \alpha}
$$

where the required reliability, $R_{S}$ is defined as $95 \%$. $S_{C}$ with a $95 \%$ confidence level is calculated as $\mathrm{S}_{\mathrm{R}}=2.1$

$\mathrm{S}_{\mathrm{T}}$ is specimen coefficient to modify the differences between the specimen and actual structure in topography. $\mathrm{S}_{\mathrm{T}}$ is determined as $\mathrm{S}_{\mathrm{T}}=1.3$ combined with a number of tests and actual statistical results.

Finally, the DFR of a structural detail can be calculated as:

$$
D F R=\frac{(1-R) \sigma_{m 0}}{0.94 \sigma_{m 0} / \sigma_{\max } S^{(5-\lg N)}-\left(0.47 S^{(5-\lg N)}-0.53\right)-R\left(0.47 S^{(5-\lg N)}+0.53\right)}
$$

The fatigue life reliability assessment method is applied here to a structure subjected to a constant amplitude fatigue loading. The maximal nominal stress is $\sigma_{\max }=90 \mathrm{MPa}$. The fatigue material parameters used here are $S=2$ and $\sigma_{\mathrm{m} 0}=310 \mathrm{MPa}$ for aluminum alloys.

Table 4 shows the calculated results of fatigue reliability assessment of 2198-T8 Al-Li alloys. The DFR value of 2198-T8 with riveted lap joints is 83.09MPa. 
Table 4. Statistical analysis of test results

\begin{tabular}{ccc}
\hline$\hat{\beta}$ & $\mathrm{N}_{95 / 95}$ & DFR(MPa) \\
\hline 231944 & 73242 & 83.09 \\
\hline
\end{tabular}

\section{Fractographic Analysis}

The fatigue fracture morphologies are examined under the scanning electron microscope (SEM, Quanta600) in order to investigate the fatigue properties of specimens. Fig. 3 shows the fractography of fatigue fracture surface.

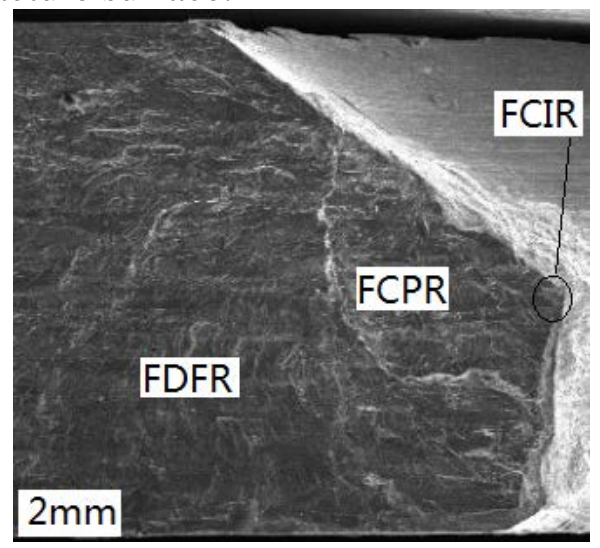

(a) SEM images of the fracture surface

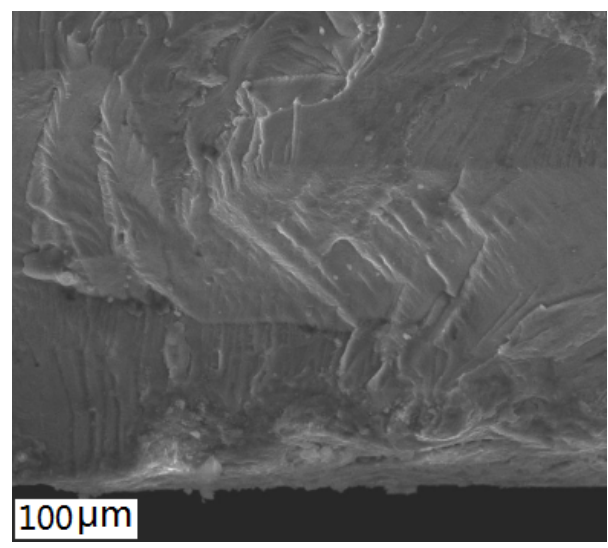

(b) Beach marks

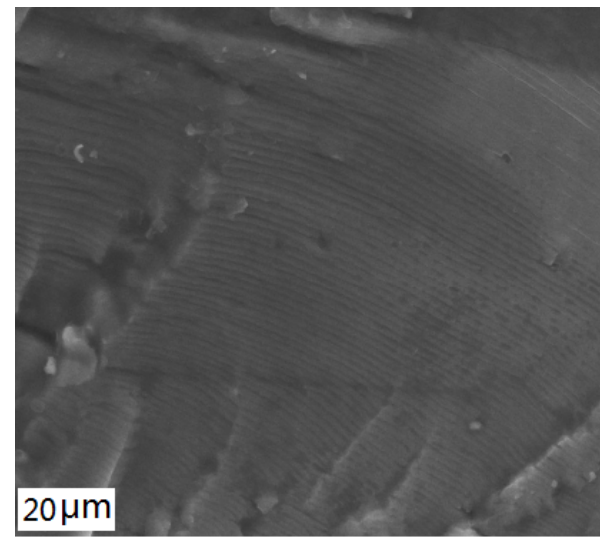

(c) Fatigue striations

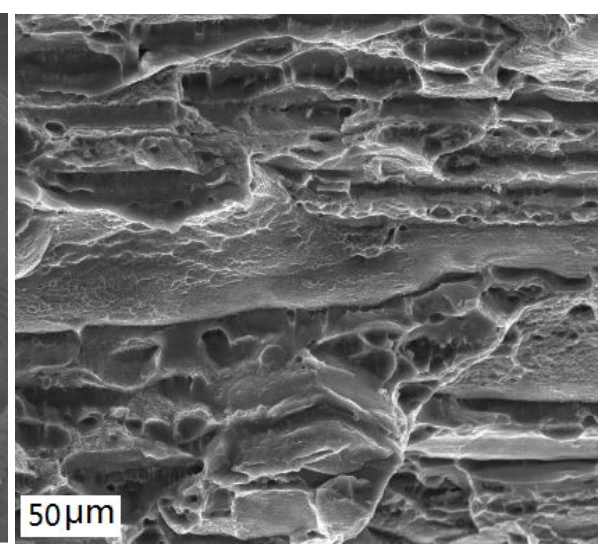

(d) Dimples and microvoids

Fig. 3. Fractography of fatigue fracture surface

The fractography is composed of three regions: fatigue crack initiation region (FCIR), fatigue crack propagation region (FCPR) and final ductile fracture region (FDFR), as seen in Fig. 3(a). Crack initiation occurred at the surface of the processing status, micro-defects and surface coarse second phase particles. Fig. 3(b) shows the beach marks which constitute fatigue crack front progression marks in the FCIR. FDFG (Fig. 3(c)) shows the typical features of fatigue striations which appear smoothly and uniformly spaced. Broken coarse second phase particles falling in the fatigue striations form some holes at the stage of fatigue crack propagation. At the end of the fatigue region, Fig. 3(d) shows different sizes of dimples and microvoids, which is typical evidences of the unstable propagation phase in a fatigue mechanism with the fracture characteristic of static tension.

\section{Conclusions}


The DFR value of 2198-T8 Al-Li alloy with riveted lap joints is calculated as 83.09MPa based on the fatigue experimental results. The fractography of fatigue fracture surface contains three typical regions, which are FCIR, FCPR and FDFR. The smooth and neat fatigue striations in FCPR of joints structure is the main reason for superior characteristics of 2198-T8 Al-Li alloy.

\section{References}

[1] Rioja R J, Liu J. The evolution of Al-Li base products for aerospace and space applications, Metallurgical and Materials Transactions A. 2012 1-13.

[2] Heinz A, Haszler A, Keidel C, Moldenhauer S, Benedictus R, Miller W S, Recent development in aluminium alloys for aerospace applications, Mater Sci Eng A. A280 (2000) 102-107.

[3] N. D. Alexopoulos, E. Migklis, A. Stylianos, D. P. Myriounis, Fatigue behavior of the aeronautical Al-Li(2198) aluminum alloy under constant amplitude loading, International Journal of Fatigue. 56 (2013) 95-105.

[4] Wu J G, Wang Q Z, Zhang X, Wang Z P, Detail Stress Analysis and Fatigue Crack Initiation Life Prediction of Riveted Joint, Acta Aeronautica et Astronautica Sinica. 2007 28(2) 336-339.

[5] M. Skorupa, A. Skorupa, T. Machniewicz, A. Korbel, Effect of production variables on the fatigue behaviour of riveted lap joints, International Journal of Fatigue. 32 (2010) 996-1003.

[6] Chen Y J. Hand Book of Durability and Damage Tolerance Design for Flight Structure, Fatigue Analysis for Flight Structure, Xi'an Aeronautics and Astronautics Ministry Scientific Design Academy, 1989.

[7] Chu K H, Xue J C, Equivalent nominal stress and determination of structural DFR under variable amplitude, Acta Aeronaut Astronaut Sin. 199112 (2) 120-124.

[8] Cohen A C, Maximum likelihood estimation in the Weibull distribution based on complete and on censored samples, Technometrics. 19657 (4) 579-588.

[9] Lin Fujia, Structural Reliability Analysis, Xi'an Northwestern Polytechnical University Press, 1991. 